\title{
Tipikal Rencana Pengamanan Air Minum (RPAM) Operator Untuk Sumber Air Baku Dari Mata Air
}

\author{
VADEL AVICENA IQBAL, RACHMAWATI S DJ, IR., M.ENV., STUD. PH.D \\ Jurusan Teknik Lingkungan, Fakultas Teknik Sipil dan Perencanaan \\ Institut Teknologi Nasional Bandung \\ Email : Avicenavadel@gmail.com
}

\begin{abstract}
ABSTRAK
Pada Tahun 2015, pemerintah membuat Rencana Pembangunan Jangka Menengah Nasional (RPJMN), dengan target 100\% akses air minum untuk semua penduduk indonesia hingga pada tahun 2019, dengan menggunakan salah satu strategi yaitu meningkatkan efisiensi pelayanan air minum melalui RPAM yang memenuhi prinsip $4 K$ (kualitas, kuantitas, kontinuitas dan keterjangkauan). Tahun 2012 Kementerian PUPR mengeluarkan manual RPAM-Operator untuk menyusun RPAM dan dapat digunakan untuk semua jenis sumber air baku. Manual RPAM-Operator yang dikeluarkan oleh kementerian PUPR yang ada pada saat ini masih bersifat umum karena sumber air baku yang digunakan lebih dari satu, maka dengan adanya bentuk tipikal RPAM-Operator untuk sumber air baku dari mata air, diharapkan dapat mempermudah PDAM dalam menyusun dokumen RPAM sehingga target RPJMN tahun 2019 dapat tercapai. Penyusunan dokumen tipikal RPAM ini dilakukan dengan mengkompilasi dokumen RPAM-Operator PDAM Kota Payakumbuh, Kota Bandung, Kota Salatiga, Kota Malang serta Kabupaten Bandung. Dari hasil penyusunan bentuk tipikal RPAM Operator untuk sumber air baku dari mata air, didapat 48 kejadian bahaya dan 44 rencana perbaikan yang dapat digunakan PDAM penyelenggara sebagai acuan dalam penyusunan RPAM di perusahaannya.
\end{abstract}

Kata kunci: RPAM, PDAM, Mata Air, Water Safety Plan.

\begin{abstract}
In the Year 2015, the government made National Medium-Term Development Plan with the purpose of Supporting 100\% access to drinking water for all residents of Indonesia until 2019, by using one strategy of improving the efficiency of drinking water services through RPAM by meeting the principles quantity, quality and continuity. In 2012 the Ministry of PUPR issued RPAM-Operator manual for preparing RPAM and can be used for all types of raw water sources. The existing RPAM documents are still common since the raw water sources are used more than one so with the the form of typical RPAM-Operator to a raw water source spring water, expected to facilitate PDAM in preparing documents RPAM so that the target the RPJMN in 2019 can be achieved.Preparation of typical RPAM this was done in compiles documents RPAM-Operator PDAM Kota Payakumbuh, PDAM Kota Bandung, PDAM Kota Salatiga, PDAM Kota Malang and PDAM Kabupaten Bandung. From the preparation of the typical RPAM-Operator for spring water source, 48 hazard risks have been obtained and 44 improvement have been proposed as a guide to RPAM document preparation in other PDAMS.
\end{abstract}

Keywords: RPAM, PDAM, Spring Water, Water Safety Plan. 


\section{PENDAHULUAN}

\section{$1.1 \quad$ Latar belakang}

Pada tahun 2014 akses pelayanan air minum yang aman di konsumsi di Indonesia hanya $70 \%$. Target pelayanan akses air minum di Indonesia pada tahun 2019 adalah $100 \%$, tertuang pada Rencana Pembangunan Jangka Menengah Nasional (RPJMN) yaitu 100-0100. Salah satu strategi RPJMN untuk mendukung tercapainya target air bersih yaitu dengan RPAM, sehingga dapat meningkatkan efisiensi sistem penyediaan air minum yang memenuhi prinsip 4K (kualitas, kuantitas, kontinuitas dan keterjangkauan) (RPJMN 2015 - 2019, 2015).

RPAM adalah upaya pengamanan air minum yang memenuhi aspek kualitas, kuantitas, kontinuitas dan keterjangkauan (4K) mulai dari sumber hingga konsumen. RPAM mengadopsi pengelolaan SPAM dari Water Safety Plan (WSP) yang dikeluarkan Worlds Health Organization (WHO). Menurut WHO, WSP merupakan cara paling efektif untuk memastikan secara konsisten keamanan suplai air minum dengan menggunakan pendekatan analisa dan manajemen resiko secara menyeluruh yang mencakup semua langkah yang ada dalam suplai air minum mulai dari sumber air sampai dengan konsumen (Kementerian PUPR, 2012).

PDAM merupakan operator penyediaan air minum di Indonesia, untuk itu penyusunan RPAM disusun dengan menggunakan dokumen manual RPAM-Operator yang dikeluarkan oleh Kementerian PUPR. Bebeberapa PDAM telah menyusun dokumen RPAM-Operator tersebut, dan rencananya RPAM-Operator tersebut akan disusun ke seluruh PDAM yang ada di Indonesia secara bertahap. Untuk itu, dibuatkan sebuah Tipikal RPAM-Operator yang disusun berdasarkan adanya kesamaan sumber air baku. Sehingga PDAM yang akan menyusun RPAM-Operator akan dimudahkan dalam penyusunan.

Perencanaan bentuk tipikal RPAM-Operator ini mengacu pada dokumen Manual RPAMOperator yang dikeluarkan oleh Kementerian PUPR pada Tahun 2012. Yang terdiri dari 11 modul diantaranya modul 1 sampa dengan 9 merupakan tahapan perencanaan, modul 10 dan 11 merupakan langkah yang berisikan pelaksanaan dan evaluasi, namun dalam penyusunan bentuk tipikal ini yang dibahas hanya 4 modul, hal ini dikarenakan hanya 4 modul inilah yang dapat disusun dalam bentuk tipikal. 4 modul tersebut yaitu pembuatan tipikal rantai pasok, penyusunan tipikal identifikasi kejadian bahaya, penyusunan tipikal tindakan pengendalian dan penyusunan tipikal rencana perbaikan.

\subsection{Maksud dan Tujuan}

Maksud dari penyusunan Tipikal RPAM-Operator untuk sumber air baku dari mata air adalah memberikan pelayanan air yang aman kepada masyarakat dari segi 4K (Kualitas, Kuantitas, Kontinuitas dan Keterjangkauan). Adapun tujuan dari perencanaan ini adalah:

- Membuat tipikal bentuk rantai pasok pada SPAM yang menggunakan sumber mata air 
- Membuat tipikal potensi kejadian bahaya dan resiko pada SPAM yang menggunakan sumber mata air.

- Membuat tipikal tindakan pengendalian dari kejadian bahaya.

- Membuat tipikal rencana perbaikan dari kejadian bahaya serta resiko yang ada di pada SPAM yang menggunakan sumber mata air.

\section{METODOLOGI}

Tahapan yang dilakukan dalam melakukan penyusunan tugas akhir ini dikelompokkan menjadi 2 yaitu tahap pengumpulan data dan tahap pengolahan $\&$ analisis data.

\subsection{Tahap Pengumpulan Data}

- Pengumpulan data sekunder

Pengumpulan data sekunder adalah teknik pengumpulan data dengan mengutip dari data-data yang telah ada sebelumnya. Adapun data sekunder yang digunakan yaitu :

- Teori yang berkaitan dengan sistem penyediaan air minum;

- Dokumen manual RPAM-Operator yang dikeluarkan oleh Kementerian PUPR;

- Dokumen RPAM-Operator PDAM Kota Payakumbuh pada Tahun 2014, Kota Bandung pada Tahun 2014, Kota Salatiga pada Tahun 2013, Kota Malang Pada Tahun 2013 dan Kabupaten Bandung pada Tahun 2014.

- Pengumpulan data primer

Pengumpulan data primer adalah teknik pengumpulan data dengan melakukan observasi langsung di lapangan. Observasi lapangan di lakukan dengan survey langsung ke sumber air baku mata air pada PDAM Tirta Raharja Kabupaten Bandung. Pengumpulan data primer ini bertujuan untuk mengetahui kondisi eksisting lokasi sistem penyediaan air minum (SPAM) mulai dari sumber, transmisi, pengolahan, distribusi sampai ke pelayanan.

\subsection{Tahap Pengolahan dan Analisis Data}

Menurut Aedi (2010), pengolahan dan analisis data meliputi kegiatan pengeditan data, tranformasi data (coding), serta penyajian data sehingga diperoleh data yang lengkap dari masing-masing obyek untuk setiap variabel yang diteliti. Metoda-metoda yang dilakukan dalam pengolahan data dapat dilihat pada Tabel 1.

Tabel 1 Metode Pelaksanaan

\begin{tabular}{clllll}
\hline Modul & Keluaran & \multicolumn{1}{c}{ Data } & Jenis Data & $\begin{array}{c}\text { Pengumpulan } \\
\text { Data }\end{array}$ & $\begin{array}{c}\text { Pengolahan } \\
\text { Data }\end{array}$ \\
\hline $\begin{array}{c}\text { M2 } \\
\text { Rantai pasok }\end{array}$ & $\begin{array}{l}\text { Gambar } \\
\text { diagram alir } \\
\text { rantai pasok }\end{array}$ & $\begin{array}{l}\text { Elevasi dan } \\
\text { Komponen SPAM }\end{array}$ & $\begin{array}{l}\text { Kualitatif, } \\
\text { Sekunder }\end{array}$ & $\begin{array}{l}\text { Tabulasi } \\
\text { Diagram alir }\end{array}$ & $\begin{array}{l}\text { Analisa } \\
\text { deskriptif }\end{array}$ \\
\cline { 2 - 6 } & $\begin{array}{l}\text { Deskripsi } \\
\text { rantai pasok }\end{array}$ & $\begin{array}{l}\text { Kode lokasi, } \\
\text { Simbol dan } \\
\text { Deskripsi }\end{array}$ & $\begin{array}{l}\text { Kualitatif, } \\
\text { Sekunder }\end{array}$ & Tabulasi & $\begin{array}{l}\text { Analisa } \\
\text { deskriptif }\end{array}$ \\
$\begin{array}{c}\text { M3 } \\
\text { Investigasi } \\
\text { resiko }\end{array}$ & $\begin{array}{l}\text { Kejadian } \\
\text { bahaya }\end{array}$ & $\begin{array}{l}\text { List kejadian } \\
\text { bahaya pada } \\
\text { dokumen RPAM } \\
\text { acuan }\end{array}$ & Kualitatif, & Tabulasi & $\begin{array}{l}\text { Analisa } \\
\text { deskriptif }\end{array}$ \\
\hline
\end{tabular}




\begin{tabular}{|c|c|c|c|c|c|}
\hline Modul & Keluaran & Data & Jenis Data & $\begin{array}{c}\text { Pengumpulan } \\
\text { Data }\end{array}$ & $\begin{array}{c}\text { Pengolahan } \\
\text { Data }\end{array}$ \\
\hline & $\begin{array}{l}\text { Resiko } \\
\text { Kejadian } \\
\text { bahaya }\end{array}$ & $\begin{array}{l}\text { Tinggi, Sedang } \\
\text { dan Rendah }\end{array}$ & $\begin{array}{l}\text { Kualitatif, } \\
\text { Primer }\end{array}$ & Tabulasi & $\begin{array}{l}\text { Pemikiran } \\
\text { logis }\end{array}$ \\
\hline & Kondisi ideal & $\begin{array}{l}\text { Peraturan terkait } \\
4 \mathrm{~K}\end{array}$ & $\begin{array}{l}\text { Kualitatif, } \\
\text { Sekunder }\end{array}$ & Tabulasi & $\begin{array}{l}\text { Analisa } \\
\text { deskriptif }\end{array}$ \\
\hline & Skor resiko & $\begin{array}{l}\text { Skor resiko pada } \\
\text { dokumen RPAM } \\
\text { acuan. }\end{array}$ & $\begin{array}{l}\text { Kuantitatif, } \\
\text { Sekunder }\end{array}$ & Tabulasi & $\begin{array}{l}\text { Pemikiran } \\
\text { logis }\end{array}$ \\
\hline \multirow[t]{2}{*}{$\begin{array}{c}\text { M4(1-2) } \\
\text { Daftar } \\
\text { Tindakan } \\
\text { Pengendalian }\end{array}$} & $\begin{array}{l}\text { Tindakan } \\
\text { pengendalian }\end{array}$ & $\begin{array}{l}\text { Tindakan } \\
\text { pengendalian pada } \\
\text { dokumen RPAM } \\
\text { acuan. }\end{array}$ & $\begin{array}{l}\text { Kualitatif, } \\
\text { Sekunder }\end{array}$ & Tabulasi & $\begin{array}{l}\text { Analisa } \\
\text { deskriptif }\end{array}$ \\
\hline & Cara Validasi & - & $\begin{array}{l}\text { Kualitatif, } \\
\text { Primer }\end{array}$ & Tabulasi & $\begin{array}{l}\text { Pemikiran } \\
\text { logis }\end{array}$ \\
\hline \multirow[t]{5}{*}{$\begin{array}{c}\text { M5 } \\
\text { Rencana } \\
\text { Perbaikan }\end{array}$} & Tema besar & $\begin{array}{l}\text { Terkait data } \\
\text { tindakan } \\
\text { pengendalian yang } \\
\text { sama (sudah } \\
\text { teridentifikasi pada } \\
\text { M4) }\end{array}$ & $\begin{array}{l}\text { Kualitatif, } \\
\text { Primer }\end{array}$ & Tabulasi & $\begin{array}{l}\text { Pemikiran } \\
\text { logis }\end{array}$ \\
\hline & $\begin{array}{l}\text { Rencana } \\
\text { Perbaikan }\end{array}$ & $\begin{array}{l}\text { Disesuaikan } \\
\text { dengan tindakan } \\
\text { pengendalian } \\
\text { (sudah } \\
\text { teridentifikasi pada } \\
\text { M4) }\end{array}$ & $\begin{array}{l}\text { Kualitatif, } \\
\text { Primer }\end{array}$ & Tabulasi & - \\
\hline & $\begin{array}{l}\text { Referensi } \\
\text { Kejadian } \\
\text { bahaya }\end{array}$ & - & $\begin{array}{l}\text { Kualitatif, } \\
\text { Primer }\end{array}$ & Tabulasi & - \\
\hline & Jenis Resiko & - & $\begin{array}{l}\text { Kualitatif, } \\
\text { Primer }\end{array}$ & Tabulasi & - \\
\hline & $\begin{array}{l}\text { Penanggung } \\
\text { jawab }\end{array}$ & PDAM & $\begin{array}{l}\text { Kualitatif, } \\
\text { Sekunder }\end{array}$ & Tabulasi & $\begin{array}{l}\text { Analisa } \\
\text { deskriptif }\end{array}$ \\
\hline
\end{tabular}

\section{PEMBAHASAN}

\subsection{Penyusunan Rantai Pasok}

Rantai pasok merupakan kerangka dasar dalam penyusunan RPAM yang harus didesain sedetail mungkin dan dilengkapi dengan penjelasan yang jelas dan akurat, sehingga dapat mempermudah dalam mengidentifikasi kejadian bahaya dan resiko-resiko yang dapat timbul. Keluaran yang ada pada rantai pasok yaitu gambar diagram alir dan tabel deskripsi rantai pasok. Langkah awal dalam penyusunan rantai pasok yaitu merekap bentuk dan jenis dari elevasi yang ada pada dokumen PDAM acuan dalam bentuk tabulasi, seperti yang terlihat pada Tabel 2 


\begin{tabular}{|c|c|c|c|c|}
\hline No. & PDAM Kota & Elel & & Sistem \\
\hline \multirow[t]{4}{*}{1} & \multirow[t]{4}{*}{ Kota Payakumbuh } & \multirow[t]{2}{*}{ Sumber-Reservoir } & Landai (jauh) & Pompa \\
\hline & & & Datar & - \\
\hline & & \multirow[t]{2}{*}{ Reservoir-Pelayanan } & Datar & - \\
\hline & & & Landai (jauh) & Pompa \\
\hline \multirow[t]{2}{*}{2} & \multirow[t]{2}{*}{ Kota Malang } & Sumber-Reservoir & Turunan & BPT \\
\hline & & Reservoir-Pelayanan & Datar & - \\
\hline \multirow[t]{4}{*}{3} & \multirow[t]{4}{*}{ Kota Salatiga } & \multirow[t]{2}{*}{ Sumber-Reservoir } & Datar (jauh) & Pompa \\
\hline & & & Mendaki & Pompa \\
\hline & & \multirow[t]{2}{*}{ Reservoir-Pelayanan } & Datar (jauh) & Pompa \\
\hline & & & Datar & - \\
\hline \multirow[t]{3}{*}{4} & \multirow[t]{3}{*}{ Kota Bandung } & \multirow[t]{2}{*}{ Sumber-Reservoir } & Turunan & BPT \\
\hline & & & Datar & - \\
\hline & & Reservoir-Pelayanan & Datar (jauh) & Pompa \\
\hline \multirow[t]{4}{*}{5} & \multirow[t]{4}{*}{ Kabupaten Bandung } & Sumber-Reservoir & Turunan & BPT \\
\hline & & \multirow[t]{3}{*}{ Reservoir-Pelayanan } & Landai (jauh) & Pompa \\
\hline & & & Turunan & BPT \\
\hline & & & Datar & - \\
\hline
\end{tabular}

Dari tabel elevasi diatas dapat dilihat, ada dua jenis sistem yang digunakan pada SPAM yaitu sistem pompa dan sistem bak pelepas tekan (BPT). Bak pelepas tekan dibuat untuk menghindari tekanan yang tinggi, sehingga tidak akan merusak sistem perpipaan yang ada. Idealnya bak ini dibuat bila maksimal mempunyai beda tinggi 70-100 meter tergantung dari kualitas pipa yang digunakan. Sedangkan sistem pompa digunakan apabila titik a lebih rendah dari pada titik b, maka sistem yang digunakan yaitu sistem pompa. Setelah mengetahui elevasi dari setiap daerah acuan, maka tipikal rantai pasok dapat dibuat kedalam tiga jenis yaitu rantai pasok tanpa BPT dan Pompa, rantai pasok menggunakan BPT dan rantai pasok menggunakan pompa. Bentuk tiga tipikal rantai pasok ini dapat dilihat pada Gambar 1
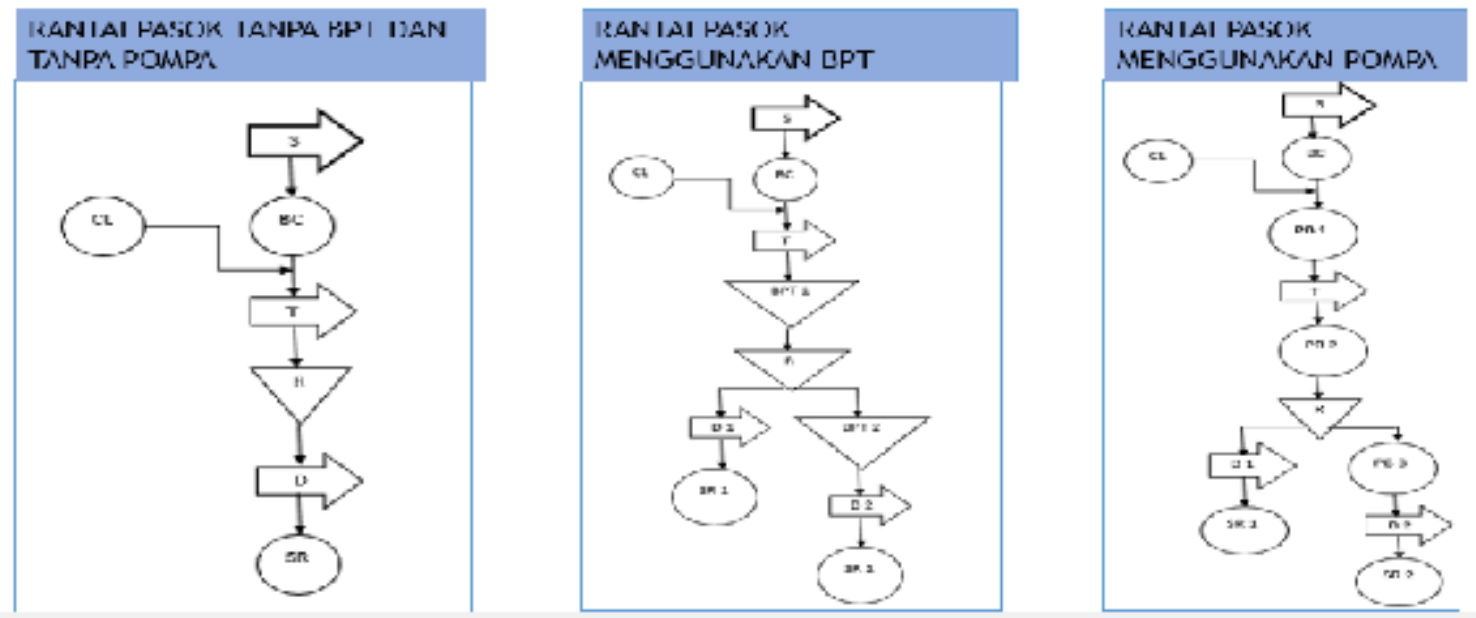

Gambar 1 tiga jenis tipikal rantai pasok 


\section{A. Rantai Pasok Tanpa Bak Pelepas Tekan (BPT) dan Tanpa Pompa}

Rantai pasok tanpa BPT dan tanpa pompa ini tidak menggunakan komponen SPAM seperti penggunaan bak pelepas tekan maupun pompa, karna pada rantai pasok jenis ini pengalirannya berjalan secara gravitasi. Keuntungan rantai pasok tanpa BPT dan tanpa pompa ini yaitu dapat mengurangi biaya tambahan seperti biaya perbaikan BPT atau pompa apabila ada kerusakan. Selain itu proses pengalirannya cukup mudah dan biaya pemeliharaan yang rendah. Contoh PDAM acuan yang menggunakan rantai pasok jenis ini yaitu, PDAM Kabupaten Bandung yang terdapat pada Mata Air Cikudapati.

\section{B. Bentuk Rantai Pasok Dengan BPT}

Pada rantai pasok ini pengaliran yang digunakan yaitu menggunakan BPT, Diasumsikan letak sumber mata air di sumber lebih tinggi dibanding dengan pemukiman penduduk menyebabkan adanya selisih tinggi permukaan. Beda tinggi ini menyebabkan adanya tekanan dalam pipa. Semakin besar selisih ketinggiannya, akan semakin besar tekanan dalam pipa. Untuk itu, tekanan perlu dilepas atau dihilangkan. Cara paling mudah mengatasi beda tinggi tersebut yaitu menggunakan BPT. Beda tinggi yang dimaksud sangat tergantung pada jenis pipa. Biasanya untuk jenis PVC (Polyvinyl Chloride) dan ACP (Asbestos Cement Pipe), beda tinggi maksimum untuk penempatan BPT adalah 70 meter. Untuk jenis pipa lainnya dapat mengikuti standar nasional maupun standar internasional yang berlaku. Untuk daerah pelayanan diasumsikan ada dua bentuk yaitu, menggunakan BPT dengan yang tidak menggunakan BPT. Contoh PDAM acuan yang menggunakan rantai pasok jenis ini yaitu PDAM Kota Malang yang mengalirkan air dari Mata Air Banyuning.

\section{Bentuk Rantai Pasok Dengan Bantuan Pompa}

Rantai pasok jenis ini sistem pengalirannya menggunakan bantuan pompa, hal ini dikarenakan sumber air berada di lokasi dengan elevasi lebih rendah dari pada lokasi yang dilayani, sehingga diperlukan pompa untuk mendorong air agar sampai ke pelanggan dengan tekanan yang cukup. Untuk daerah pelayanan diasumsikan ada dua bentuk yaitu menggunakan pompa dengan yang tidak menggunakan pompa. Contoh PDAM acuan yang menggunakan rantai pasok jenis ini yaitu PDAM Kota Payakumbuh yang mengalirkan air dari Mata Air Batang Tabik.

Tabel deskripsi rantai pasok (Tabel 4) didapatkan dari dokumen manual RPAM-Operator yang dikeluarkan Kementrerian PUPR berupa kode lokasi dan simbol, seperti yang terlihat pada tabel 4.

Tabel 3 Simbol-simbol rantai pasok

\begin{tabular}{ll}
\hline \\
$\longrightarrow$
\end{tabular}


Tabel 4 Deskripsi Rantai Pasok

Kode Lokasi Simbol Deskripsi

- Kode lokasi yang digunakan, dapat berupa singkatan dari nama komponen rantai pasok.

- Simbol yang digunakan dalam pembuatan rantai pasok, seperti yang dijelaskan pada tabel 3

- Deskripsi, proses apa yang terjadi di komponen rantai pasok tersebut.

\subsection{Investugasi Risiko}

Tujuan dari dilakukannya investigasi risiko di setiap komponen rantai pasok adalah untuk mengidentifikasi dan menginventarisir potensi kejadian bahaya yang dapat timbul pada rantai pasok, dan juga untuk memperkirakan risiko-risiko apa saja yang dapat ditimbulkan oleh kejadian bahaya tersebut. Dari risiko-risiko yang telah teridentifikasi, akan diberikan skor atau nilai untuk dapat mengetahui risiko-risiko yang signifikan dan yang tidak signifikan dengan menggunakan metode matriks. Kejadian bahaya pada modul 3 ini didapatkan dari analisa deskriptif terhadap kejadian bahaya yang ada pada dokumen RPAM acuan dan untuk mengetahui resiko dari kejadian bahaya tersebut maka dilakukan analisa dari pemikiran logis berdasarkan resiko yang mungkin terjadi terhadap kejadian bahaya. Penentuan kondisi ideal didapatkan dari analisa deskriptif terhadap peraturan terkait 4K. Adapun standar yang digunakan dapat dilihat pada tabel 5. keluaran dari modul 3 ini yaitu tabel investigasi risiko seperti yang terlihat pada tabel 6

\begin{tabular}{|c|c|c|}
\hline \multicolumn{3}{|c|}{ Tabel 5 Standar aman berdasarkan sasaran 4K } \\
\hline Jenis Resiko & & Standar \\
\hline $\begin{array}{l}\text { Kualitas } \\
\text { (K1) }\end{array}$ & \multicolumn{2}{|c|}{$\begin{array}{l}\text { Aman dari segi kualitas dan memenuhi standar Kepmenkes RI No.492 tahun } \\
2010 \text { tentang persyaratan kualitas air minum. }\end{array}$} \\
\hline $\begin{array}{l}\text { Kuantitas } \\
\text { (K2) }\end{array}$ & \multicolumn{2}{|c|}{$\begin{array}{l}\text { Aman dari segi kuantitas dan memenuhi standar Permen PU RI No.01 tahun } \\
2014 \text { tentang standar pelayanan minimal bidang pekerjaan umum dan } \\
\text { perumahan rakyat yaitu } 60 \text { liter/orang/hari kebutuhan air minimum. }\end{array}$} \\
\hline \multirow[t]{2}{*}{ Kontinuitas (K3) } & \multirow{2}{*}{$\begin{array}{l}\text { Aman dari segi kontinuitas dan } \\
\text { memenuhi standar Permen RI } \\
\text { No. } 27 \text { tahun } 2016 \text { tentang } \\
\text { penyelenggaraan sistem } \\
\text { penyediaan air minum. }\end{array}$} & $\begin{array}{l}\text { Lampiran VII jaminan pengaliran } 24 \\
\text { jam/hari }\end{array}$ \\
\hline & & $\begin{array}{l}\text { Lampiran III tekanan minimum sebesar } \\
0,5-1,0 \text { atm di titik pelayanan kritis }\end{array}$ \\
\hline $\begin{array}{l}\text { Keterjangkauan } \\
\text { (K4) }\end{array}$ & \multicolumn{2}{|c|}{$\begin{array}{l}\text { Aman dari segi keterjangkauan. Tarif air minum tidak melebihi } 4 \% \text { dari } \\
\text { pendapatan masyarakat dan memenuhi Permen Dalam Negeri No.71 tahun } \\
2016 \text { tentang perhitungan dan penetapan tarif air minum. }\end{array}$} \\
\hline
\end{tabular}

Sumber : Manual RPAM-Operator, Ditjen Cipta Karya, 2014 
Tabel 6 Contoh Tabel Potensi Kejadian Bahaya serta Nilai Skor Resikonya

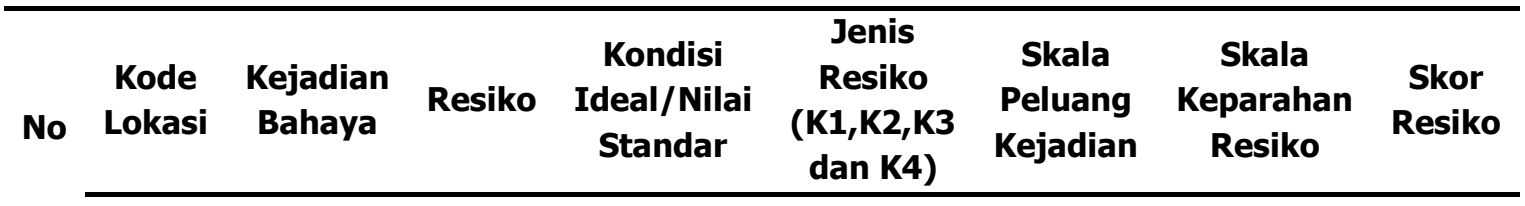

Sumber : Manual RPAM-Operator, Ditjen Cipta Karya 2014

Untuk penentuan nilai skor resiko didapat dengan cara mengkalikan peluang kejadian bahaya dengan tingkat keparahan resikonya. Untuk angka skala peluang kejadian bahaya dan skala keparahan risiko dapat dilihat pada Tabel 7 dan Tabel 8.

Tabel 7 Peluang dan Skala Kejadian Bahaya

\section{Peluang kejadian}

Skala

Hampir selalu (peluang kejadian setiap hari) 5

Sering (setiap minggu) 4

Sedang (setiap bulan) 3

Jarang (setiap tahun) 2

Sangat jarang (lebih dari 1 tahun sekali) 1

(Kementerian Pekerjaan Umum, 2014)

Tabel 8 Tingkat dan Skala Keparahan Resiko

\begin{tabular}{lc}
\hline \multicolumn{1}{c}{ Keparahan resiko } & Skala \\
\hline Sangat parah & 5 \\
\hline Besar & 4 \\
\hline Sedang & 3 \\
\hline Kecil & 2 \\
\hline Sangat kecil/ tak berarti & 1 \\
\hline
\end{tabular}

(Kementerian Pekerjaan Umum, 2014)

Tabel 9 Matriks Penetapan Keparahan Skor Risiko

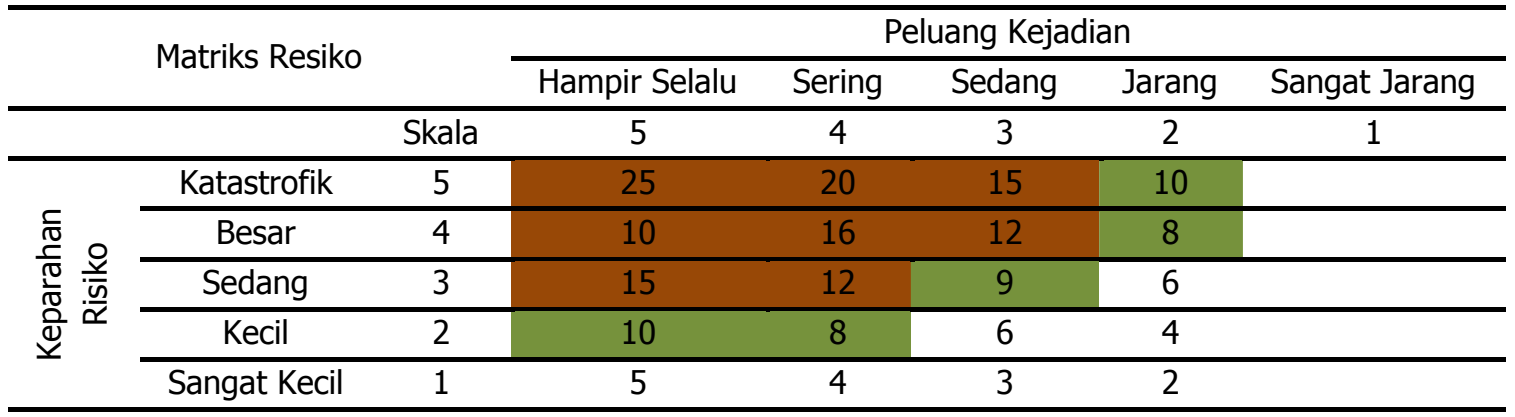

Sumber : Manual RPAM-Operator, Ditjen Cipta Karya 2014

Tabel 9 menunjukkan bahwa skor risiko:

- $\quad \mathbf{1 2}$, adalah risiko tinggi yang memerlukan tindakan segera. 
- 8 - $<\mathbf{1 2}$ adalah batasan risiko sedang.

- $\quad \mathbf{8}$ adalah batasan risiko rendah dan tidak memerluan tindakan penanganan segera

\subsection{Daftar Tindakan Pengendalian}

Tujuan membuat daftar tindakan pengendalian adalah untuk menanggulangi atau menangani kejadian bahaya dari resikonya. Setiap tindakan pengendalian, disertai dengan cara validasi tindakan pengendalian tersebut. Tujuan dilakukan validasi pada setiap tindakan pengendalian adalah untuk mengetahui tindakan pengendalian yang digunakan efektif dan membuahkan hasil sesuai dengan apa yang diharapkan. Metode yang digunakan mengetahui tindakan pengendalian adalah analisa deskriptif dengan cara menganalisa tindakan pengendalian yang terdapat pada dokumen RPAM acuan dan disesuaikan dengan kejadian bahaya beserta resiko yang sudah teridentifikasi. Untuk validasi didapat dari pemikiran logis atas tindakan pengendalian. Dokumen yang dihasilkan dari penyusunan M4(1-2) adalah tabel tindakan pengendalian dan cara validasinya seperti yang terlihat pada tabel 10

Tabel 10 Contoh Tabel Daftar Tindakan Pengendalian dan Cara Validasinya

\begin{tabular}{cccc}
\hline $\begin{array}{c}\text { Kejadian } \\
\text { Bahaya }\end{array}$ & Resiko & $\begin{array}{c}\text { Tindakan } \\
\text { Pengendalian }\end{array}$ & Cara Validasi \\
\hline
\end{tabular}

Sumber : Manual RPAM-Operator, Ditjen Cipta Karya, 2014

Petunjuk pengisian Tabel 10:

- Kolom kejadian bahaya dan risiko merupakan kejadian bahaya dan risiko yang telah diidentifikasi pada Tabel 6;

- Alternatif tindakan pengendalian didapat dari alternatif tindakan pengendalian yang digunakan;

- Kolom validasi diisi dengan menentukan cara validasi dari tiap tindakan pengendalian.

\subsection{Rencana Perbaikan}

Tujuan dilakukan penyusunan rencana perbaikan adalah untuk menangani kejadian bahaya dan resiko yang telah teridentifikasi dan yang telah diprioritaskan pada tahapan sebelumnya. Penetuan tema besar didapat dari pemikiran logis atas pengelompokan kejadian bahaya yang sama. Untuk rencana perbaikan, referensi kejadian bahaya dan jenis resiko disesuaikan dengan modul sebelumnya yang sudah teridentifikasi. Penanggung jawab didapatkan dari dokumen RPAM acuan dan disesuaikan dengan rencana perbaikan. Dokumen yang dihasilkan dari penyusunan M5 adalah tabel 11 rencana perbaikan dari kejadian bahaya 
Tabel 11 Contoh Tabel Rencana Perbaikan

\begin{tabular}{|c|c|c|c|c|c|}
\hline No & $\begin{array}{c}\text { Tema Besar } \\
\text { Dari Kejadian } \\
\text { Bahaya }\end{array}$ & $\begin{array}{l}\text { Rencana } \\
\text { Perbaikan }\end{array}$ & $\begin{array}{c}\text { Referensi } \\
\text { Kejadian } \\
\text { Bahaya yang } \\
\text { Ditangani }\end{array}$ & $\begin{array}{l}\text { Jenis Risiko } \\
4 K(K 1, K 2, \\
\text { K3 atau K4) }\end{array}$ & $\begin{array}{c}\text { Penanggung Jawab: } \\
\text { Departemen/Bagian } \\
\text { (dan Person in } \\
\text { Charge) }\end{array}$ \\
\hline
\end{tabular}

Sumber : Manual RPAM-Operator, Ditjen Cipta Karya 2014

Petunjuk pengisian Tabel 11:

- Tema besar yaitu tema yang didapat dari penggabungan beberapa kejadian bahaya dan risiko yang mirip satu sama lain, baik jenis maupun lokasi kejadiannya;

- Kolom rencana perbaikan merupakan rencana perbaikan/alternatif tindakan pengendalian yang terkait dengan tema besar;

- Referensi kejadian bahaya disesuaikan dengan jenis risiko yang sudah teridentifikasi sebelumnya M3;

- Jenis risiko disesuaikan dengan jenis risiko yang sudah teridentifikasi sebelumnya M3;

- Kolom penanggung jawab : Merupakan penanggung jawab dari rencana perbaikan yang dilakukan.

\section{KESIMPULAN}

Dari hasil penyusunan bentuk Tipikal Rencana Pengamanan Air Minum (RPAM)-Operator untuk sumber air baku yang berasal dari mata air, dapat ditarik kesimpulan sebagai berikut:

1. Bentuk tipikal rantai pasok untuk sumber air baku yang berasal dari mata air dipengaruhi oleh bentuk topografi daerah perencanaan dan penggunaan komponen Sistem Penyediaan Air Minum (SPAM). Hasil yang didapati rantai pasok terbagi menjadi 3 bentuk, yaitu rantai pasok tanpa BPT dan pompa, rantai pasok menggunakan BPT dan rantai pasok menggunakan pompa.

2. Komponen Sistem Penyediaan Air Minum (SPAM) untuk sumber air baku mata air terdiri dari sumber mata air, broncaptering, jaringan pipa transmisi, reservoir, Bak Pelepas Tekan (BPT), pompa, proses desinfeksi, jaringan pipa distribusi dan sambungan langganan.

3. Kejadian bahaya pada tiap komponen Sistem Penyediaan Air Minum (SPAM) pada tiap daerah berbeda-beda. Hal ini dipengaruhi oleh kondisi eksisting lingkungan SPAM.

4. Terdapat 48 Kejadian bahaya dan 44 Rencana Perbaikan 


\section{DAFTAR PUSTAKA}

Al-Layla M.A, Ahmad S., Middlebrooks J.E., (1980), Water Supply Engineering Design, Ann Arbor Science Publishers Inc., Michigan.

American Water Works Association (AWWA). (1984). Introduction to Water Treatment: a Basic/ Intermediate Course for Water System Operator. United State America : Universitas Indiana.

Arifiani, dkk (2007) "Reservoir digunakan pada sistem distribusi untuk meratakan aliran, mengatur tekanan dan untuk keadaan darurat"

Bitton, G. (1994). Introduction to Enviromental Virology. New York: Wiley.

Cahyana, Gede H. (2010). Sistem Transmisi, Dalam Majalah Air Minum Edisi 178, Jakarta.

Damanhuri. (1989). Sistem ini meliputi unsur sistem perpipaan dan perlengkapannya, tekanan tersedia, sistem perpompaan (bila diperlukan) dan reservoir distribusi.

Direktorat Jenderal Cipta Karya Kementerian Pekerjaan Umum. (2014). Arahan RPJPN untuk RPJPN 3 Bidang Cipta Karya. Arahan Direktur Jenderal Cipta Karya Kebijakan Program Bidang Cipta karya. Palembang: Direktorat Jenderal Cipta Karya Kementerian Pekerjaan Umum.

Direktorat Jenderal PPM dan PLP. (1997). Penyehatan Air : Materi Pelatihan bagi Petugas Kesehatan Lingkungan Daerah TK II. Direktorat Jenderal PPM dan PLP Departemen Kesehatan RI. Jakarta.

Enger dan Smith, (2000), Dalam Tasambar Mochtar, Aspek Pengelolaan Air dan Sumber Air dalam Era Otonomi Daerah.

Gabriel, Bitton. (1994). Wastewater Microbiology. A Jhon Wiley \& Sons, INC. New York. Hamer, Mark J. (1975), Water and Waste Water Technology, John Wiley \& sons, Inc,

Joko, Tri. (2010). Unit Air Baku dalam Sistem Penyediaan Air Minum. Edisi Pertama Yogyakarta; Graha Ilmu.

Kamala. (1999). Environmental Engineering : Water Supply sanitary Engineering and Pollution, McGraw Hill publishing Company Ltd.

Kodoatie, RJ. dan Sjarief, Rustam. (2005). Pengelolaan Sumber Daya Air Terpadu. Yogyakarta.

Kementerian Pekerjaan Umum dan Perumahan Rakyat. (2014). Manual Rencana Pengamanan Air Minum (RPAM) Operator, Direktorat Pengembangan Air Minum Ditjen Cipta Karya. Jakarta.

Kementerian Pekerjaan Umum dan Perumahan Rakyat. (2015). Petunjuk Teknis Penilaian Kinerja PDAM, Badan Pendukung Pengembangan Sistem Penyediaan Air Minum.

Manual Rencana Keamanan Air, Tuntunan Manajemen Resiko Untuk Pemasok Air Minum, Water Health Organization (WHO).

Noerbambang, M.S dan Morimura, T. (2000). Perencanaan dan Pemeliharaan Sistem Plambing. PT Pradnya Paramita. Jakarta.

PDAM Kota Payakumbuh. (2014). Dokumen Rencana Pengamanan Air Minum Kota Payakumbuh. Kota Payakumbuh

PDAM Kota Salatiga. (2013). Dokumen Rencana Pengamanan Air Minum Kota Salatiga. Kota Salatiga.

PDAM Kota Bandung. (2013). Dokumen Rencana Pengamanan Air Minum Kota Bandung. Kota Bandung. 
PDAM Kabupaten Bandung. (2014). Dokumen Rencana Pengamanan Air Minum Kabupaten Bandung. Kabupaten Bandung.

Peraturan Menteri Kesehatan Republik Indonesia Nomor 492. (2010). Tentang Persyaratan Kualitas Air Minum.

Peraturan Pemerintah Pekerjaan Umum Nomor 14. (2010). Tentang Standar Pelayanan Kualitas Air.

Peraturan Pemerintah Republik Indonesia Nomor 82 Tahun (2001). Tentang Pengelolaan Kualitas Air dan Pengendalian Pencemaran Air.

Peraturan Pemerintah Republik Indonesia Nomor 122 Tahun (2015). Tentang Sistem Penyediaan Air Minum.

Peavy, Howard S et.al. (1985). Environmental Engineering. McGraw-Hill. Singapore.

Rizki, L. (2014). Visual Cerdas Indonesia. Retrieved from. http://www.visualcerdasindonesia. com/designs/44.

Reynolds, T.D. (1982). Unit Operations And processes In Environmental Engneering. California: Brooks/ Cole Engineering Division.

Said, NI. (2010). Desinfeksi untuk Proses Pengolahan Air Minum. Jakarta : Pusat Teknologi Lingkungan. 